\title{
BMJ Open The use of information and communication technologies to promote healthy lifestyle behaviour: a systematic scoping review
}

\author{
Elizabeth Musili Joseph-Shehu (D) , ${ }^{1,2}$ Busisiwe Purity Ncama, ${ }^{1}$ \\ Nomaxabiso Mooi (D) , ${ }^{1}$ Tivani Phosa Mashamba-Thompson (D) ${ }^{1}$
}

To cite: Joseph-Shehu EM, Ncama BP, Mooi N, et al. The use of information and communication technologies to promote healthy lifestyle behaviour: a systematic scoping review. BMJ Open 2019;9:e029872. doi:10.1136/ bmjopen-2019-029872

- Prepublication history and additional material for this paper are available online. To view these files, please visit the journal online (http://dx.doi. org/10.1136bmjopen-2019029872).

Received 18 February 2019 Revised 16 September 2019 Accepted 07 October 2019

Check for updates

(c) Author(s) (or their employer(s)) 2019. Re-use permitted under CC BY-NC. No commercial re-use. See rights and permissions. Published by BMJ.

${ }^{1}$ Nursing, University of KwaZuluNatal College of Health

Sciences, Durban, South Africa

${ }^{2}$ Nursing Science, National

Open University of Nigeria, Jabi, Nigeria

Correspondence to Dr Elizabeth Musili Joseph-

Shehu;

ejoseph-shehu@noun.edu.ng

\section{ABSTRACT}

Introduction Health-promoting lifestyle behaviours are part of the activities of daily living that influence individual happiness, values and well-being. They play a crucial role in prevention and control of non-communicable diseases (NCDs) among all age groups. Current statistics on mortality, disability and morbidity associated with NCDs are alarming globally. The use of information and communication technology (ICT) for a health-promoting lifestyle behaviour programme enhances health behaviours that are important in the prevention and control of both communicable and non-communicable diseases. Our study aimed to map evidence on the use of ICT in comprehensive health-promoting lifestyle behaviour among healthy adults.

Methods Eleven electronic databases were searched for the study. We included studies published in English between January 2007 and December 2018 reporting on healthy adults, ICT and any subscales of the healthpromoting lifestyle profile (HPLP). Studies focusing on diseases or disease management and studies that combine monitoring tools in the form of hardware (accelerometer or pedometer) with ICT or computer games were excluded. Data were summarised numerically and thematically.

Results All the studies reviewed were conducted in developed countries. Most of the studies reported on physical activity, and findings of one study covered all the subscales of HPLP. The use of ICT for health-promoting lifestyle behaviours was reported to be effective in ensuring health behaviours that can improve physical and mental health.

Conclusion Our findings showed that there is a dearth of knowledge on comprehensive health-promoting lifestyle behaviour that can be beneficial for the control and prevention of NCDs. There is a need to carry out primary studies on the use of ICT and comprehensive healthpromoting lifestyle, especially among adults in low-income and middle-income countries where there are alarming statistics for mortality and disability associated with NCDs. PROSPERO registration number CRD42016042568.

\section{INTRODUCTION}

Increase in the prevalence of non-communicable diseases (NCDs) such as chronic

\section{Strengths and limitations of this study}

- A comprehensive and extensive literature search on the use of information and communication technology (ICT) in comprehensive health-promoting lifestyle behaviour among healthy adults was done to identify research gap.

- Rigorous process was followed in searching and selecting the included articles for the study.

- Inclusion of primary research articles in the study was subjected only to Mixed Method Appraisal Tool (MMAT) V.2011.

- Only studies published in English between January 2007 and December 2018 were included in the study.

- The reference lists of the included articles were not examined, and no manual searches were performed. Lastly, only electronic databases were extensively searched for the included studies.

cardiovascular diseases, stroke, cancers, chronic respiratory diseases and diabetes mellitus calls for more proactive ways to manage, control and prevent them. Seventy per cent of global mortality has been attributed to NCDs. ${ }^{12}$ Eighty per cent of deaths associated with NCDs occur in low-income and middle-income countries (LMICs) in the 30-60 years age group. ${ }^{2-5}$ In 2013, a report showed that (Int\$) 53.8 billion was spent on NCDs globally. ${ }^{6}$ NCDs have been shown to be a major barrier to development and achievement of the millennium development goals. ${ }^{6}$ Many NCDs have a strong association with unhealthy lifestyle. ${ }^{278}$ Risk factors for NCDs are tobacco use, food high in saturated and trans fat, high consumption of sugar and salt, excessive alcohol intake, physical inactivity, poor diet, overweight and obesity, inadequate sleep and rest, stress and exposure to environmental hazards. ${ }^{9-12}$

Health-promoting lifestyle behaviour has been identified as having an essential role in 
prevention and control of NCDs. ${ }^{13-16}$ Health promotion is an umbrella term describing a composite of disease prevention and health promotion. ${ }^{3}$ Information and communication technology (ICT) has been shown to be beneficial as it has made it possible to access health-related information easily. ${ }^{17}$ The use of ICT in health promotion and health management is increasingly well recognised because of its cost-effectiveness in the prevention of diseases. ${ }^{18}$ Evidence exists that ICT is used in health surveillance for both communicable and non-communicable diseases. ICT paired with monitoring tools can improve physical activity (PA) and weight loss. ${ }^{19}$ Few individuals adhere to healthy lifestyle behaviour despite the role it plays in chronic disease prevention, and literature has shown that web-based interventions are effective in changing behaviour. ${ }^{20}$ ICT refers to technology that provides access to information and communication ${ }^{21}$ through a wide range of communication tools. In this study, ICT includes internet, cell phones, computers and websites.

The use of ICT in management and prevention of diseases is on the increase. ICT applications are used in psychotherapeutic intervention, ${ }^{22}{ }^{23}$ management and control of medical conditions such as hypertension, ${ }^{24} 25$ HIV and other sexually transmitted diseases,${ }^{26}$ diabetes management, smoking cessation, asthma management, weight loss and PA. ${ }^{20} 2728$ ICT applications have also been used for recruitment of particular research groups. One good example was a study conducted by Bauermeister and his team, where they used a web version of respondent-driven sampling (webRDS) to recruit a sample of young adults (ages 18-24) and examined whether this strategy would result in alcohol and other drug prevalence estimates comparable with national estimates. ${ }^{29} \mathrm{On}$ health-promoting lifestyle and ICT, several studies have been done, mainly on PA, smoking cessation, alcohol intervention and diet for weight control. However, there are other health-promoting lifestyle behaviours such as stress management, interpersonal relationship, health responsibility and self-actualisation that are equally important to disease prevention and health promotion, along with PA and nutrition. ${ }^{11}$

We are not aware of any review that has reported on the use of ICT and the six domains of comprehensive health-promoting lifestyle behaviour (nutrition, PA, stress management, interpersonal relationships, self-actualisation/spiritual growth and health responsibility) among healthy individuals. Comprehensive health-promoting lifestyle behaviours are described for the purpose of this study as day-to-day lifestyle practices that can prevent diseases and promote health. The six health-promoting lifestyle behaviours are the subscales of the health-promoting lifestyle profile (HPLP) instrument. ${ }^{30}$ JosephShehu $e t a l^{31}$ described the HPLP subscales as follows: (1) nutrition signifies an individual's eating habits and food choices; (2) PA signifies actions engaged in by an individual that make him/her active and not sedentary; (3) health responsibility signifies knowing how to act in ways that improve one's own health; (4) stress management signifies the ability to identify factors that affect one's stress level and being able to manage such factors; (5) self-actualisation is the ability to achieve one's life goals by adopting a positive approach and drawing on one's talents and creativity; (6) spiritual growth is not specific to any particular religion; rather, it signifies ability to harness inner resources to connect with oneself and with others and having purpose in life that leads one to excel and develop in attaining life goals and possible fulfilment; (7) interpersonal relations signifies achieving meaningful and sustainable relationships with people through any form of communication. ${ }^{31}$

Each of these health-promoting lifestyle behaviours is important in the prevention and control of both communicable and non-communicable diseases, as they are part of the activities of daily living that influence individual happiness, values and well-being. ${ }^{32}$ Reports show that there was a lower risk of developing diabetes mellitus, stroke, myocardial infarction and cancers among 23153 Germans between 35 and 65 years of age that were followed for an average period of 7.8 years on adherence to no smoking, exercise, healthy diet and body mass index (BMI) less than $30 \mathrm{~kg} / \mathrm{m}^{2}$ compared with participants that did not engage in these healthy lifestyle practices. ${ }^{20}$ There is a possibility that if lifestyle practices such as stress management, interpersonal relationships, health responsibility and self-actualisation were added to the lifestyle, this could have led to lower risk for developing other NCDs such as peptic ulcer and mental illnesses. Hence, this study aimed to map evidence on the use of ICT in health-promoting lifestyle behaviour among healthy individuals to comprehensively assess the current state of knowledge on health-promoting lifestyle behaviour and ICT. The results of this study will help identify an area that requires meta-analysis and future primary research. This systematic scoping review accordingly seeks to address the following research questions:

- Does use of ICT improve and enhance health-promoting lifestyle behaviour?

- Is there any evidence that use of ICT in health-promoting lifestyle activity resulted in good health status (healthy weight, normal blood pressure, normal blood sugar, and good mental and physical health)?

\section{Methods/Designs}

This systematic scoping study was registered with PROSPERO (the International Prospective Register of Systematic Reviews): registration number CRD42016042568. The review adopted the five stages of Arksey and O'Malley's framework (identifying the research question, identifying relevant studies, study selection, charting the data, and collating, summarising and reporting the results) for conducting scoping reviews. ${ }^{33}$ The study protocol was published in BMJ Open. ${ }^{3}$ This review report was guided by PRISMA-ScR (Preferred Reporting Items for Systematic Reviews and Meta-Analysis extension for Scoping Reviews).${ }^{34}$ 
Table 1 Population, Interventions, Comparison, Outcome and Study setting (PICOS) framework for determination of the eligibility of the review questions

\begin{tabular}{ll}
\hline Criteria & Determinants \\
\hline Population & Healthy adults, workers and well individuals \\
Interventions & $\begin{array}{l}\text { Health-promoting lifestyle profile (nutrition, interpersonal relationship, health } \\
\text { responsibility, stress management, self-actualisation or spiritual growth) and } \\
\text { information and communication technologies (ICT, mobile phone, text messages, } \\
\text { SMS, internet, computers, websites) }\end{array}$ \\
Comparison & $\begin{array}{l}\text { Health-promoting lifestyle profile intervention without ICT } \\
\text { Outcomes }\end{array}$ \\
& $\begin{array}{l}\text { Effective and sustaining health-promoting lifestyle practices (nutrition, interpersonal } \\
\text { relationship, health responsibility, stress management, self-actualisation or spiritual } \\
\text { growth) and health status (normal weight, normal blood pressure, normal blood sugar } \\
\text { and good mental and physical health) }\end{array}$ \\
\hline Study setting & Focus on low-income and middle-income countries \\
\hline
\end{tabular}

Adopted from the study protocol. ${ }^{3}$

ICT, information and communication technology; PA, physical activity; SMS, short messaging service.

\section{Search strategy}

An extensive search of eligible studies was conducted on the following 11 databases: Academic Search Complete (EBSCO), PsycArticle (EBSCO), PubMed, Medline (EBSCO), CINAHL (EBSCO), Educational Source (EBSCO), Health Source: Consumer Edition (EBSCO), Health Source: Nursing Academic Edition (EBSCO), PsycINFO (EBSCO), Science Direct and Google Scholar. We searched for articles published in the English language between January 2007 and December 2018. This time frame was selected to assess work that has been done on using ICT in comprehensive health-promoting lifestyle behaviour among healthy adults over one decade. The search strategy was focused mainly on the study interventions and the population of interest (table 1). Boolean operators (AND and OR) separated keywords in the search as follows: health promoting lifestyle profile OR health-promoting lifestyle profile OR health-promoting lifestyle behaviour OR wellness OR nutrition OR diet OR physical activity OR interpersonal relationships OR health responsibility OR stress management OR self-actualisation OR spiritual growth AND information and communication technology OR ICT OR mobile phone OR text messages OR SMS OR e-health OR m-health OR the internet AND adult OR workers OR employees. Summary of the search strategy is found in the (online supplementary file 1 ).

\section{Eligibility criteria}

Inclusion criteria

- Studies reporting on healthy workers, professionals and adults.

- Studies published in the English language.

- Studies published between January 2007 and December 2018.

- Studies reporting on interventions such as one or more subscale(s) of the health-promoting lifestyle profile (stress management, interpersonal relationships, nutrition, self-actualisation/spiritual growth, health responsibility and PA) and ICT (text messages, short messaging service (SMS), computers, mobile phone, websites and internet).

- All study designs, including cross-sectional studies, quantitative studies, randomised controlled trial (RCT) studies, quasi-experimental study designs, cohort studies, qualitative studies and systematic reviews.

\section{Exclusion criteria}

- Studies which do not report on any form of ICT.

- Studies on patients, youth, students, diseases/management or children.

- Studies that do not report on all or any of the subscales of the HPLP.

- Studies that do not report on outcome of interest (table 1).

- Studies that use any form of ICT in recruitment or as a means of collecting data only.

- Literature published before January 2007 and after December 2018.

- Studies which do not report on adults.

- Studies that combine monitoring tools in the form of hardware (accelerometer or pedometer) with ICT and computer games.

- Studies reporting on alcoholism, obesity or cigarette smoking.

- Non-English publications.

- Study protocols, non-systematic review, book chapters, dissertation and letter to the editors.

\section{Study selection}

The selection process for the included articles involved rigorous exercises in three stages of screening-title, abstract and full-text screening-before data extraction. One reviewer conducted the title screening of the included articles and abstract, and full-text screening was undertaken independently by two reviewers. Any disagreement at any level of the screening was discussed until 
both reviewers reached consensus. Title of an article that was not cleared was included for abstract screening, and if abstract of an article was not cleared, same was added for the full-text screening. The reviewers developed the screening form before commencement of the screening exercise. The screening forms were developed based on population, interventions and outcomes. ${ }^{3}$ Systematic reviews were included if they met the inclusion criteria. Two independent reviewers screened the included articles full text, based on the inclusion and exclusion criteria described above, and consensus between the reviewers resolved any disagreement. The degree of agreement between reviewers at the full-text screening stage was estimated using kappa statistic with STATA V.13.

\section{Data extraction}

Data extraction criteria were determined, and a self-designed data extraction form was designed by the reviewers before data extraction to aid the process. The primary outcome measured was health-promoting lifestyle behaviours and health status (table 1). There was no restriction on how to measure the outcome such as whether physiological or self-report. However, use of accelerometer, pedometer or computer games was not included in this study. In order to provide answers to the study questions, data extracted from each of the studies included were as follows: bibliography of the study (author's name and date), location of the study, objective or aim of the study (as reported by authors), study design, study population, study setting, sample size, type of ICT (table 1), type of health-promoting lifestyle behaviour (table 1), duration of the study, outcome of the study, results or findings from the study and conclusions of the study.

\section{Quality appraisal of the included studies}

Mixed Method Appraisal Tool (MMAT) V.2011 ${ }^{35}$ was used to assess the quality of included research articles. MMAT was designed to evaluate articles on primary research using the following study designs: qualitative; quantitative and mixed method. The MMAT enabled us to assess the methodological quality of the included studies. Scores for each study varied between $25 \%$ and $100 \%$. For mixed method studies, there were 11 criteria to be met for an article to be rated as high; four criteria each for quantitative (QUANT) section and qualitative (QUAL) section and three for mixed method (MM) section. MM studies were rated as $25 \%$ when $\mathrm{QUAL}=1$ and $\mathrm{QUAN}=1$ and $\mathrm{MM}=0$; as $50 \%$ when $\mathrm{QUAL}=2$ and $\mathrm{QUAN}=2$ and $\mathrm{MM}=1$; as $75 \%$ when $\mathrm{QUAL}=3$ and $\mathrm{QUAN}=3$ and $\mathrm{MM}=2$; and as $100 \%$ when $\mathrm{QUAL}=4$ and $\mathrm{QUAN}=4$ and $\mathrm{MM}=3$. A criterion score between $25 \%$ and $49 \%$ was rated as low quality, a score of $50 \%-74 \%$ as average quality and a score of $75 \%-100 \%$ as high quality.

\section{Collating and summarising the findings}

Extracted data were summarised numerically and thematically using the following two themes: ICT used in health-promoting lifestyle behaviour and health-promoting lifestyle behaviour outcomes. The authors collectively assessed themes and conducted a critical appraisal of each theme in relation to the research questions. We also examined the meaning of the findings in relation to the aim of the study and their implications for research, practice and policy.

\section{Patient and public involvement}

Patients and the public were not involved in the study as it is a systematic scoping review.

\section{RESULTS}

The literature encompassed a broad scope of studies exploring the use of ICT in health-promoting lifestyle behaviour among healthy individuals. Eleven electronic databases searched (figure 1) yielded 10858 potential articles. After screening and duplicates were removed, 24 articles met the study inclusion criteria. The kappa statistics for the degree of agreement showed $74.5 \%$ agreement versus $49.8 \%$ expected by chance, which constitutes moderate to substantial agreement (kappa statistic $=0.49$, p-value $<0.001)$. McNemar's $\chi^{2}$ statistic suggests that there is not a statistically significant difference in the proportions of yes/no answers by reviewers. The study includes 13 research articles and 11 systematic reviews identified as meeting the inclusion criteria and focused on the specified health-promoting lifestyle behaviours and ICT among healthy adults.

\section{Characteristics of included studies in this scoping review}

The characteristics of the included studies are presented in table 2. Two of the included studies adopted MM designs ${ }^{36}{ }^{37}$; one study in each case adopted qualitative design, ${ }^{38}$ quantitative non-randomised design,${ }^{39}$ prospective longitudinal cluster-randomised controlled trial, ${ }^{40}$ retrospective randomised trial design ${ }^{41}$ and intervention study. ${ }^{42}$ Six studies ${ }^{18} 20{ }^{43-46}$ adopted RCT design. The duration of the intervention studies ranged from 4 weeks to 10 months. One of the main study aims was to determine the effect of proactive dissemination strategy on the reach of the internet-delivered computer-tailored intervention $^{42}$; study duration commenced with the invitation to participate in the study. Sample sizes of the included research articles ranged from 26 to 16948; sample sizes of the included evidence review articles ranged from 11 to $457 .^{47}$ Twelve studies focused on males and females, ${ }^{20} 36-4244-4648$ one reported on females alone, ${ }^{18}$ one reported on all study population, ${ }^{49}$ one reported on employees $^{50}$ and nine studies (systematic review) did not report study population. ${ }^{17274751-56}$ Seven of the studies reviewed were conducted in the community. ${ }^{39} 4144-464856$ Eight were conducted at the workplace: one each among the military, ${ }^{40}$ nurses,${ }^{18}$ university employees, ${ }^{36}$ municipality employees ${ }^{46}$; two in more than one organisation $^{203847}$; and two did not describe the workers. ${ }^{370}$ 


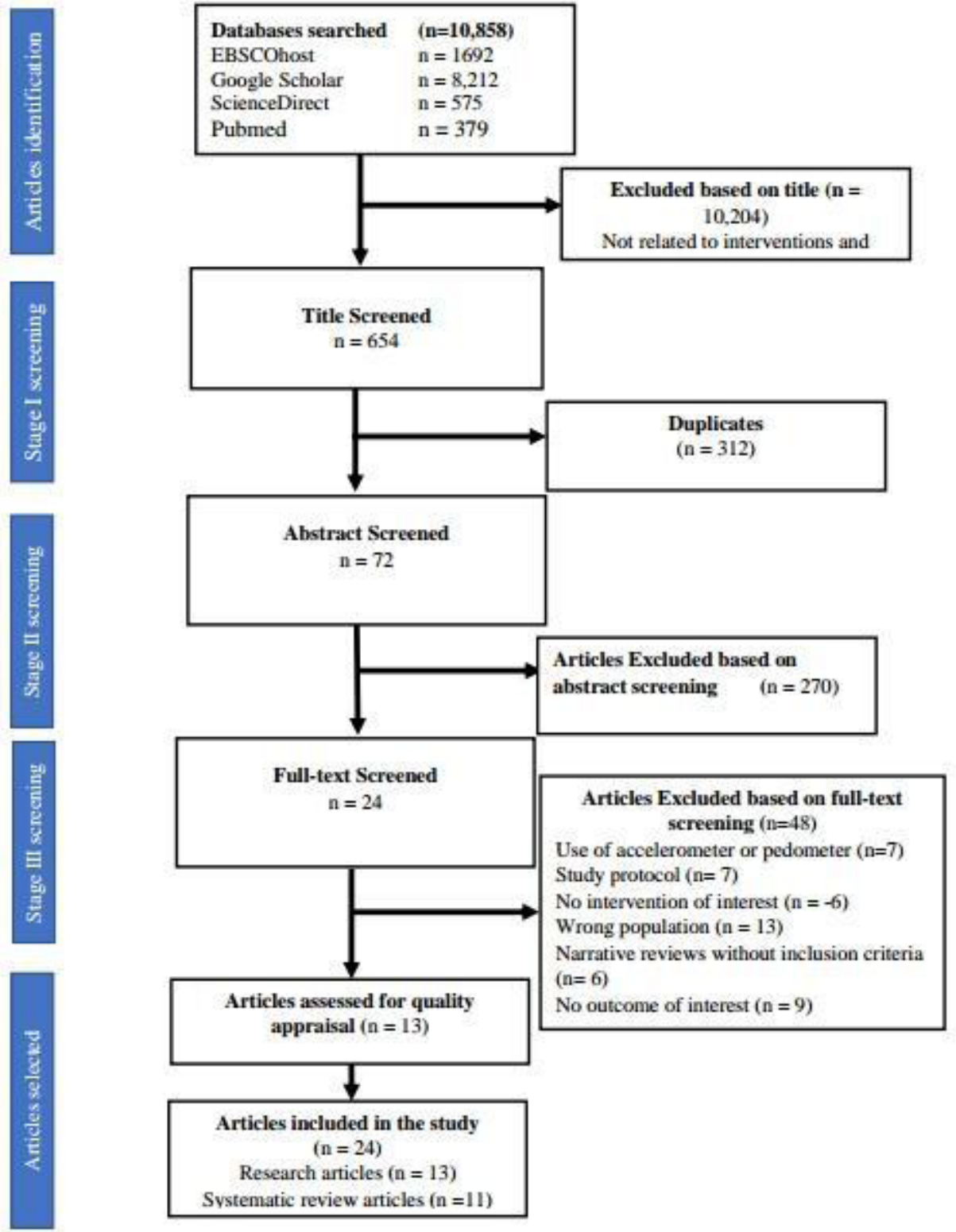

Figure 1 Flow diagram of the included article.

Five of the 11 systematically reviewed studies 2750515455 did not report the study country of included articles; one reported 457 articles from 36 countries in Asia, Australia and Oceania, Europe, North America and South America ${ }^{49}$; one reviewed 34 articles from five countries (Europe, Asia, South Korea, USA, New Zealand) ${ }^{52}$; 12 articles from three countries (USA, UK and Australia) ${ }^{17}$; 12 articles from nine countries (USA, Denmark, England, Ireland, Canada, Australia, South Korea, Israel and Singapore), ${ }^{56} 22$ articles from eight countries (USA, Australia, Netherlands, UK, Sweden, Japan, Norway and Singapore) ${ }^{47}$ and 38 articles from the USA alone. ${ }^{53}$ In regard to primary research included in this study, three studies were conducted in Australia, ${ }^{39} 4145$ three in the UK, ${ }^{36-38}$ three in the USA, ${ }^{40} 43^{44}$ two in the Netherlands, ${ }^{42}{ }^{46}$ one in Israel ${ }^{20}$ and one in Taiwan. ${ }^{18}$ Not all of the included studies reported on geographical setting of the research and none of the studies was conducted in an LMIC.

\section{Risk-of-bias assessment}

In regard to quality assessment of the included studies, the scores of the 13 articles reviewed for methodological quality ranged from $50 \%$ to $100 \%$. Nine of the reviewed articles were rated as high quality, of which three scored $100 \% \%^{4045}$ and six scored 75\%. ${ }^{18} 2038414248$ Only four were rated average quality, with two scoring $50 \%^{3946}$ and two scoring $67 \% .^{36}$ The overall quality assessment was appraised to be average risk of bias due to the following: no clear description of concealment, withdrawal rate higher than $20 \%$ and no consideration given to how findings related to researcher influence. 


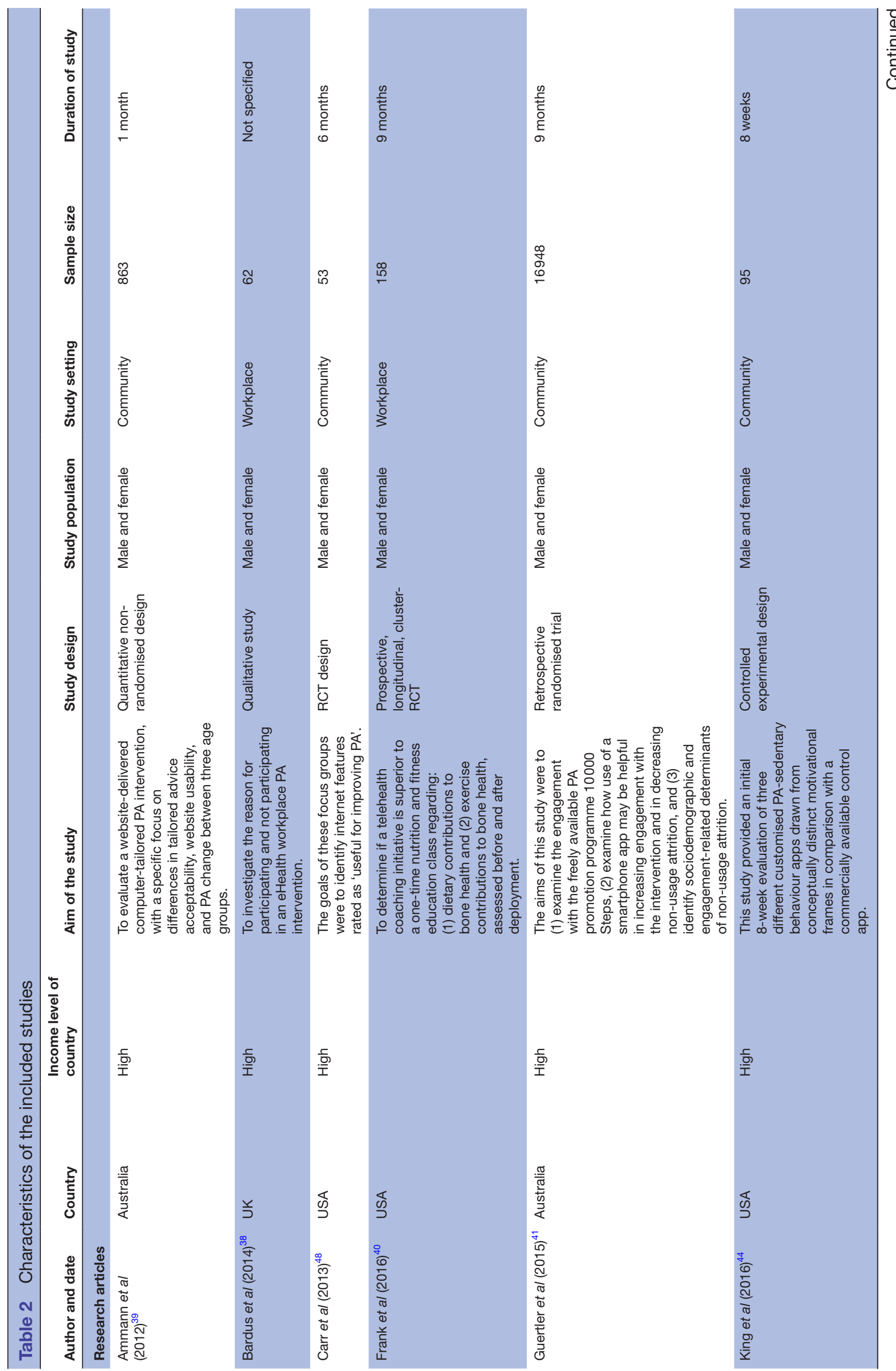




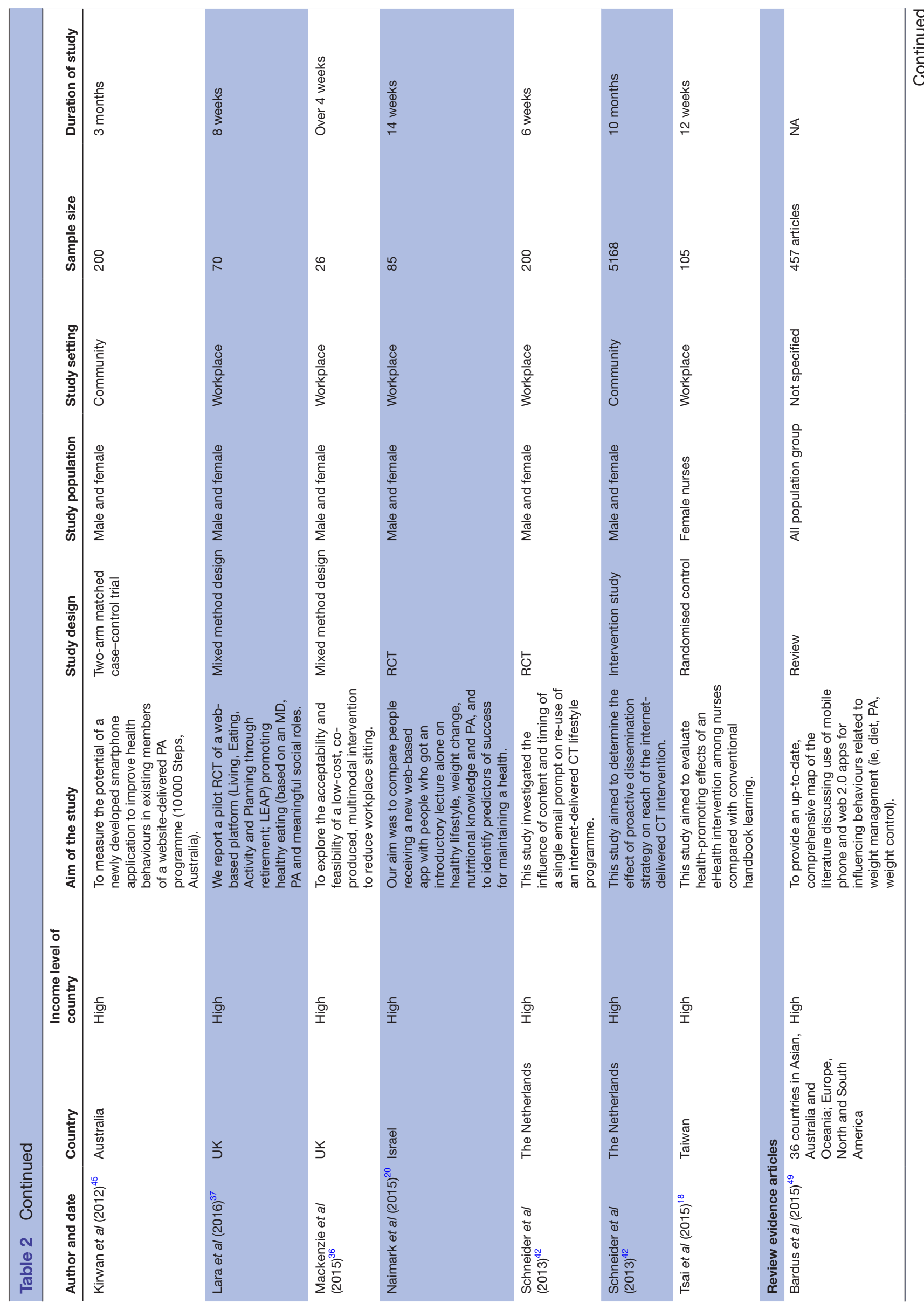




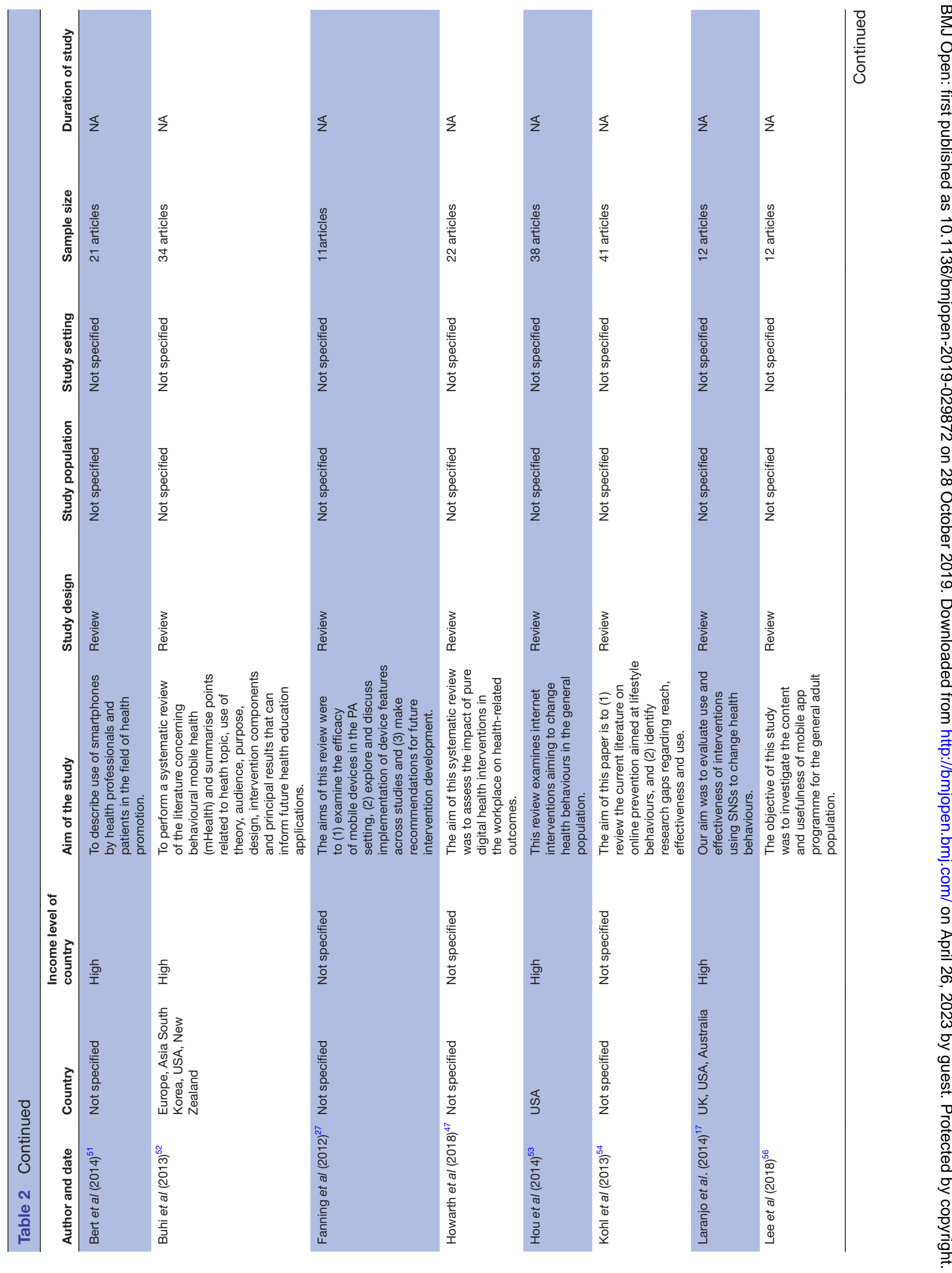

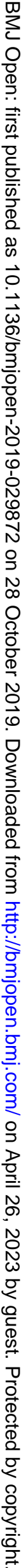




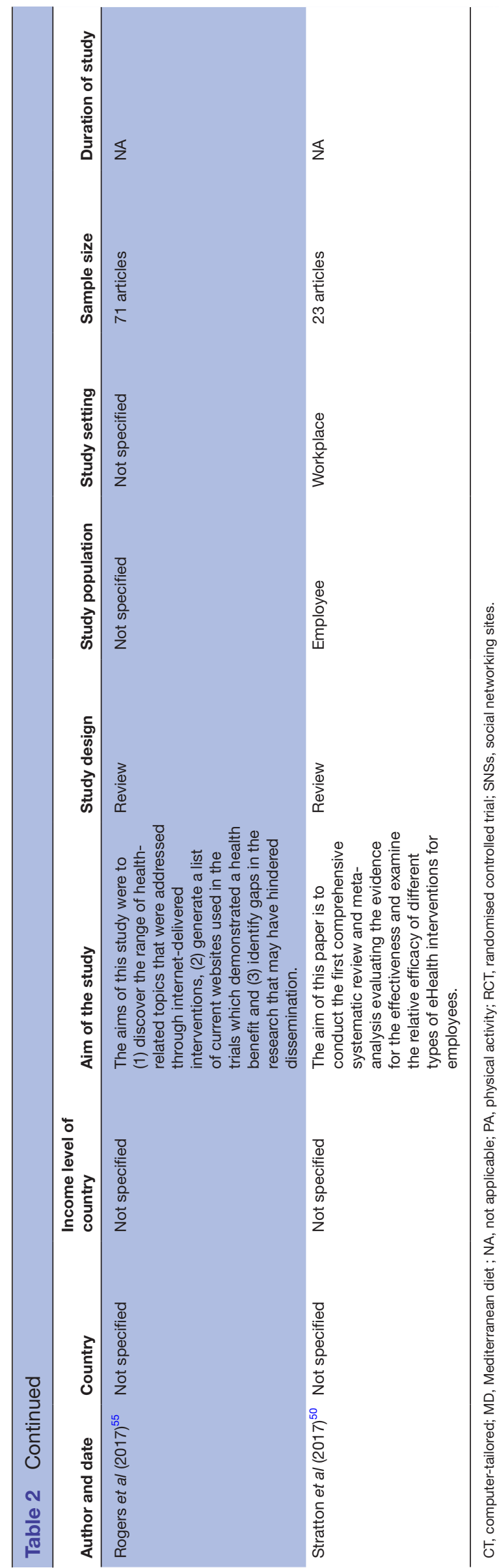

ICT use in health-promoting lifestyle behaviours

A theme emerging from the study was ICT use in health-promoting lifestyle behaviours, and health-promoting lifestyle behaviours targeted by the included studies (table 3). Various forms of ICT (email, social network sites (SNSs), websites, SMS or text messages, mobile phone app, smartphones, computers, and multimedia messaging service (MMS) ) were used in the included studies for health-promoting lifestyle behaviours intervention that targeted one form or another of health-promoting behaviours. In all the included articles the internet was obviously used via either phones or computers. However, some authors specifically mentioned use of internet in their reports, ${ }^{42} 46-485255$ and a few authors explicitly mentioned computer use. ${ }^{42} 4653$ All the reviewed studies except one $^{50}$ reported on physical activity, 13 reported on nutrition, ${ }^{18} 203740424647495153-56$ one reported on social connection, ${ }^{37}$ three reported on stress management ${ }^{45056}$ and one reported on all the subscales of health-promoting lifestyle profile. ${ }^{18}$

Use of email and website, ${ }^{39}$ email, website and SMS, ${ }^{38}$ smartphone and website, ${ }^{45} 50$ and website only ${ }^{48} 5055$ was reported only for PA behaviour. Three of the reviewed studies reported on smartphone apps, one in the form of an in-built accelerator ${ }^{44}$ and one on smartphone with website for PA behaviour. ${ }^{41}$ Fanning et al reported on use of mobile device, mobile software and SMS for PA. ${ }^{27}$ Websites, smartphone and tablet apps were reported to be used for cognitive behavioural therapy (CBT), stress management and mindfulness-based approaches. ${ }^{50}$ Five of the included studies reported on use of more than one form of ICT for more than one health behaviour. ${ }^{404795256}$ Computer-based information and communication technologies $^{53}$ and internet-delivered computer-tailored lifestyle programme ${ }^{42465}$ were reported to be used for more than one health behaviour, including PA, nutrition, alcohol use, smoking behaviour and condom use. Use of website only was reported for nutrition, PA, stress management, interpersonal relationship, spiritual growth, and health responsibility, ${ }^{18}$ and diet, PA and social connection. ${ }^{37}$

SNSs were reported for fitness, sexual health, food safety, smoking and health promotion, ${ }^{17}$ and for diet, $\mathrm{PA}$, alcohol and tobacco use, mental health intervention, disease management and sexual health. ${ }^{55}$ A specific software programme aimed at reducing sedentary behaviour in the work place. ${ }^{47}$ Mackenzie et al reported use of email, software reminder and Twitter to reduce workplace sitting only, ${ }^{36}$ while a web-based app was used for nutrition and PA only. ${ }^{20}$ A comprehensive health-promoting lifestyle behaviour was reported among female nurses only. ${ }^{18}$

\section{Use of ICT for health-promoting lifestyle behaviours and health status}

Use of any form of ICT increased participants' PA behaviour, ${ }^{27} \quad 36 \quad 39-41 \quad 44 \quad 4548$ and health behaviour change $^{172047525356}$ (table 3). Use of ICT in health-promoting behaviour was reported to reduce weight, ${ }^{20} 5556$ 


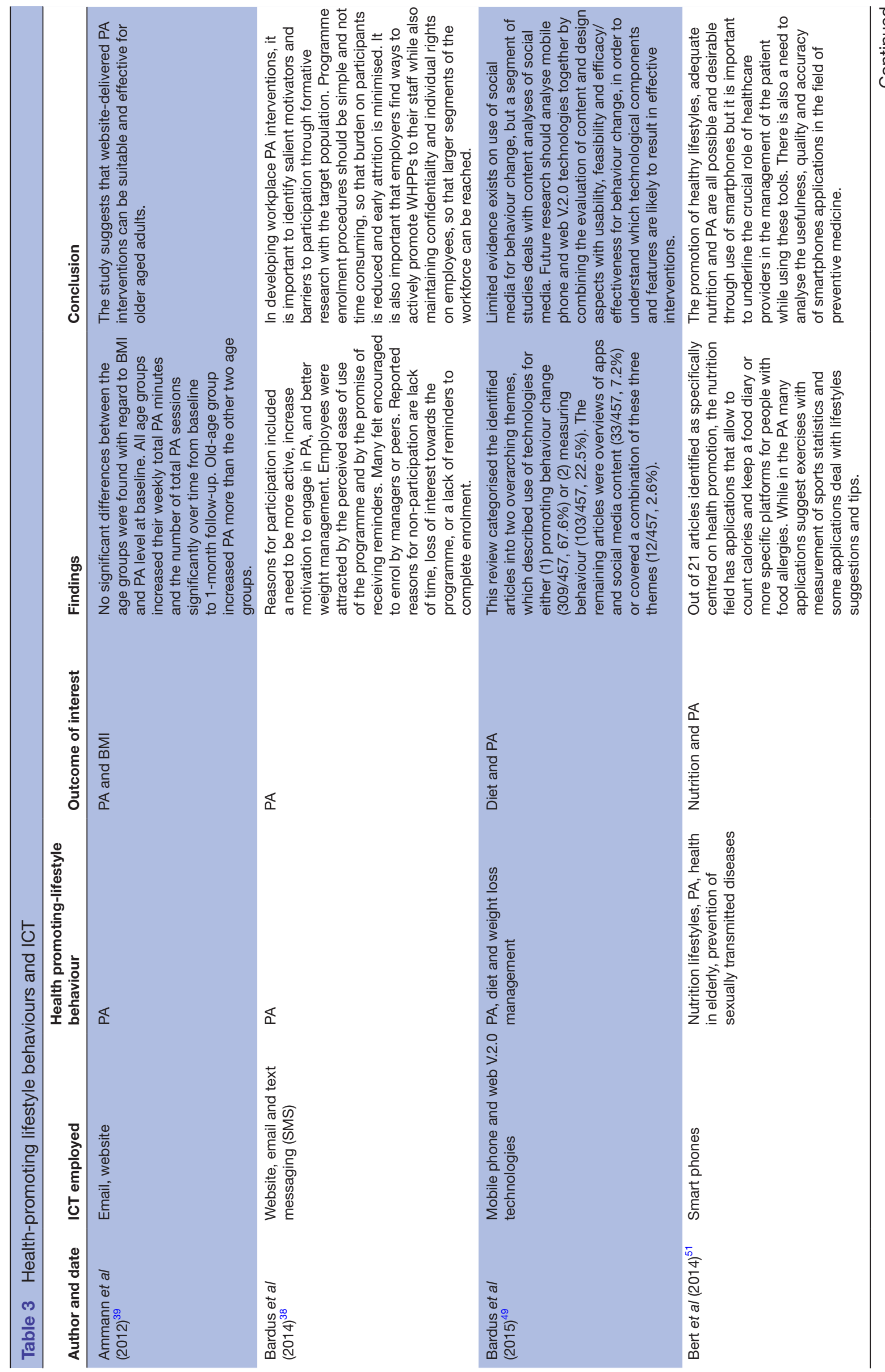




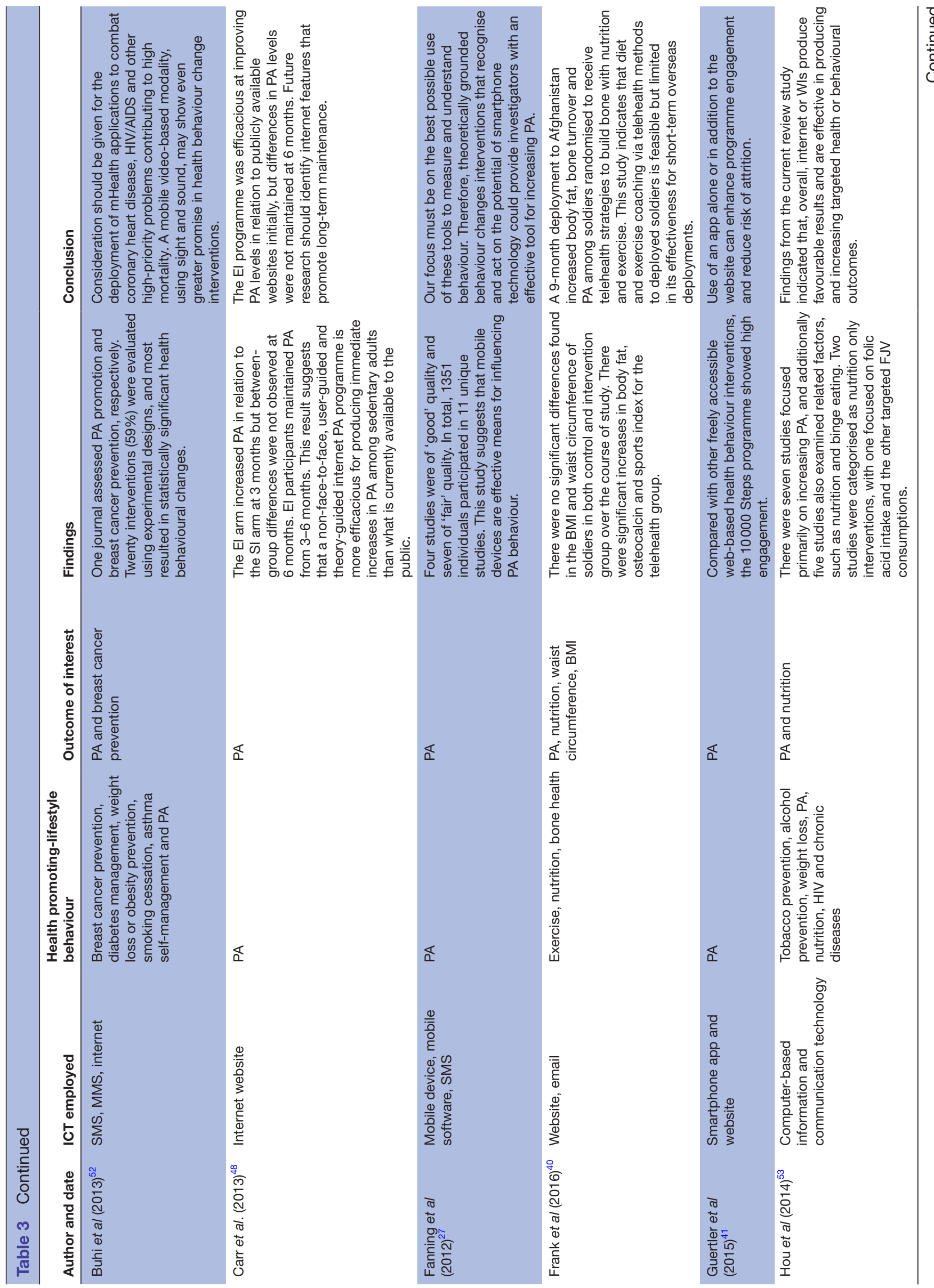




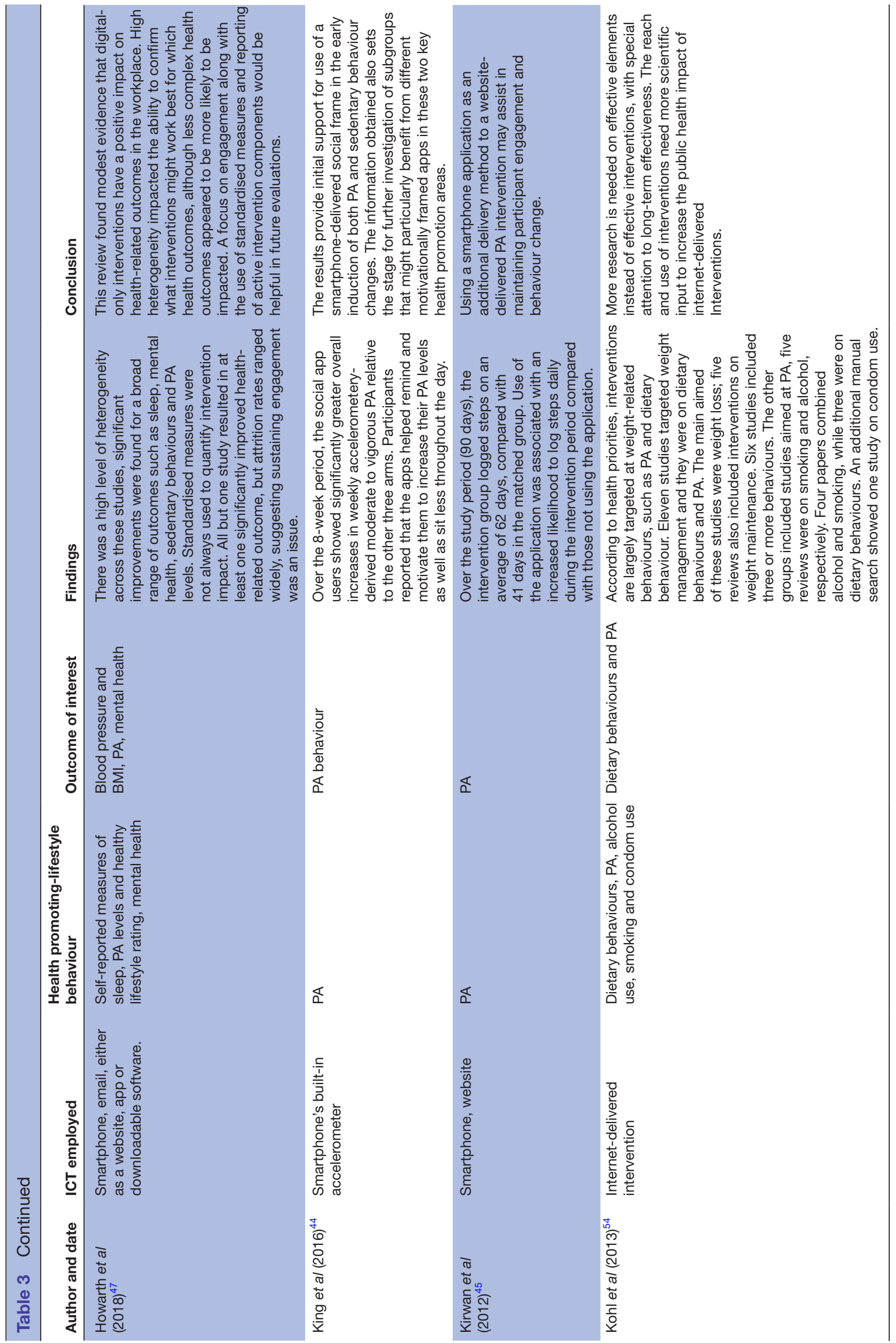




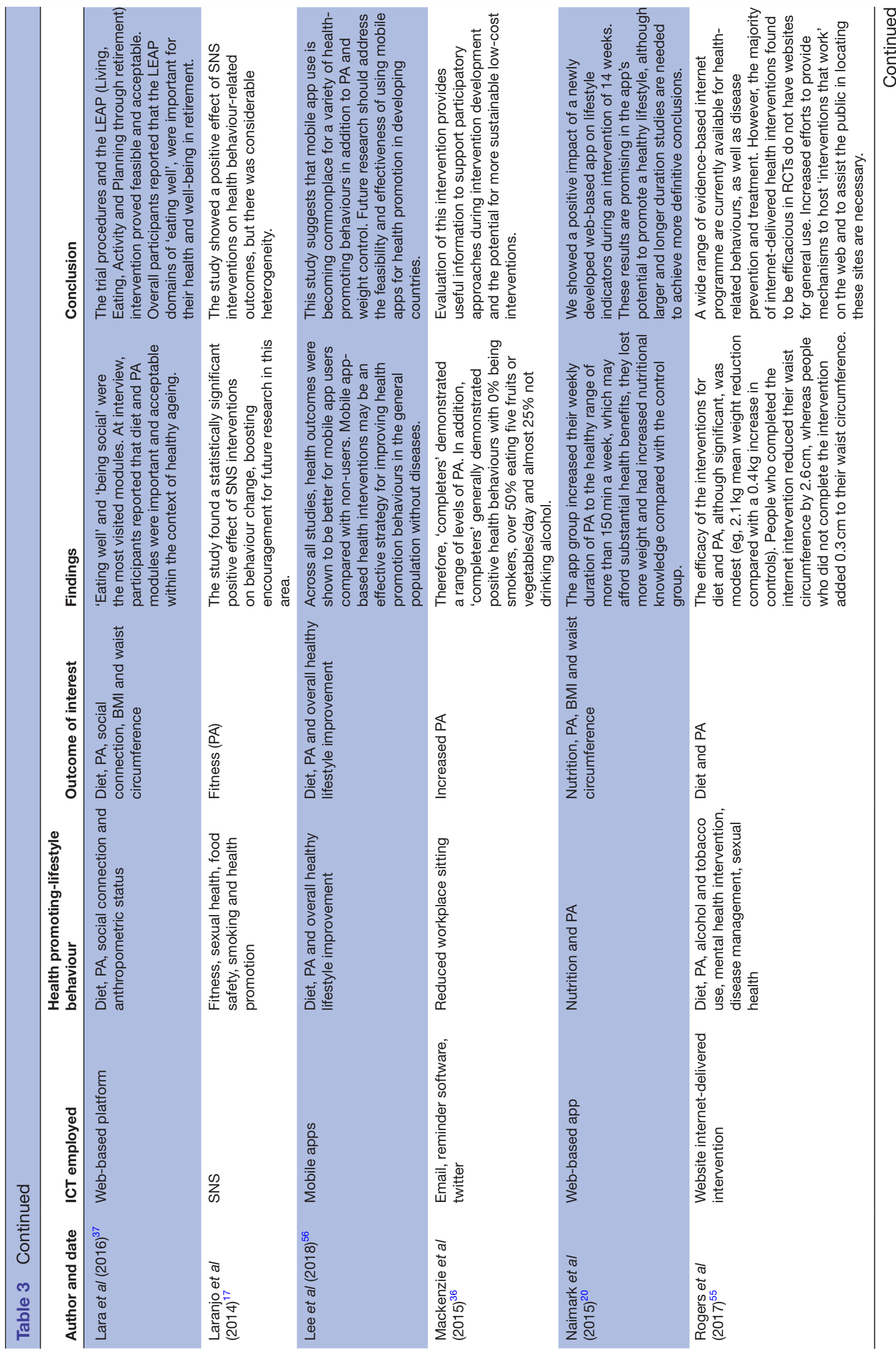




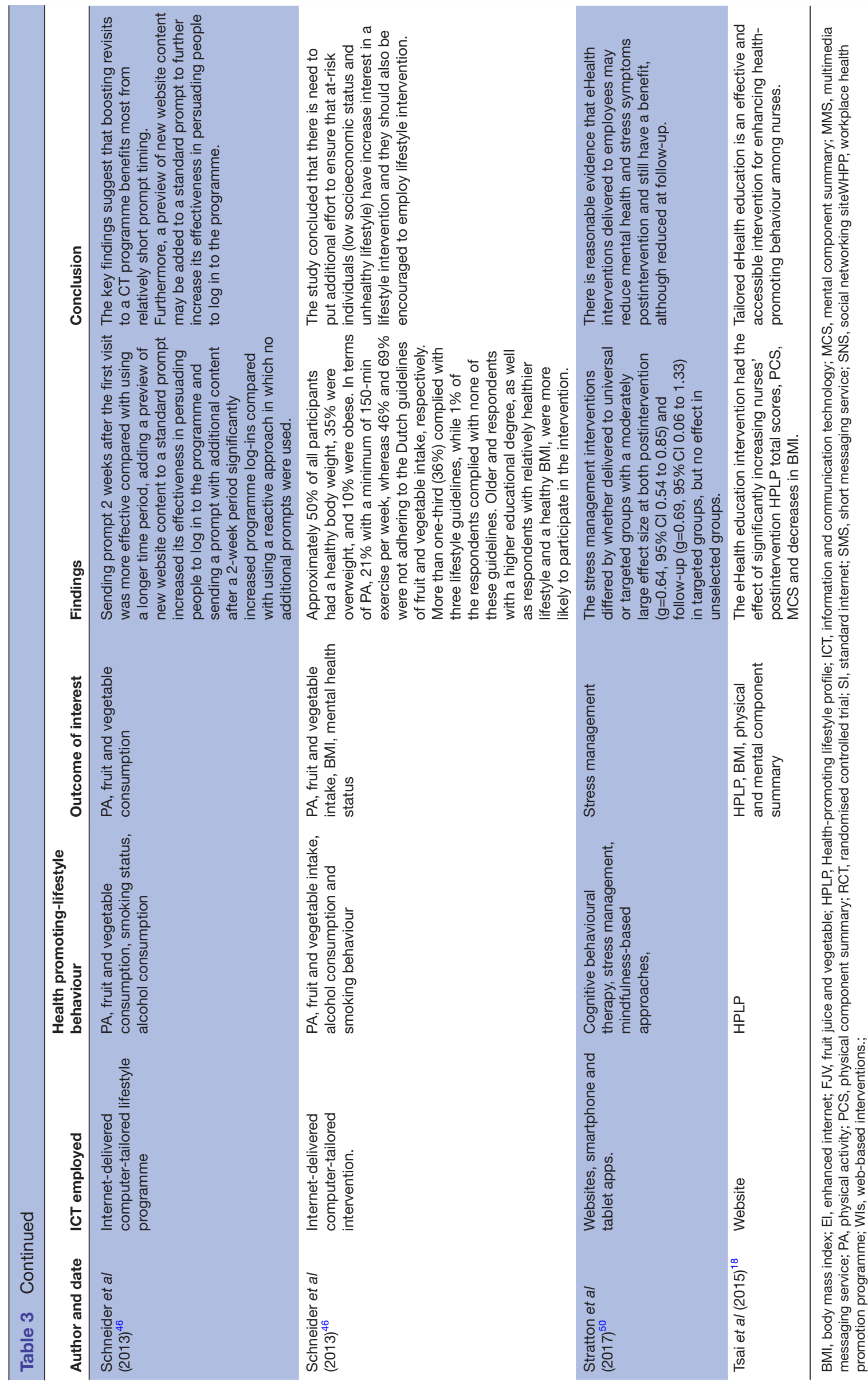


but Frank et al reported no significant difference in participants' BMI and waist circumference. ${ }^{40}$ People that are likely to participate in an internet-delivered computer-tailored intervention are older individuals with higher educational level, relative healthier lifestyle and healthy BMI. ${ }^{42}$ For efficient use of internet-delivered computer-tailored lifestyle programme, a preview of new website content should be included in a standard prompt in addition to short prompt timing. ${ }^{46}$ Factors to be considered when planning intervention for ICT to be used for health-promoting lifestyle behaviours in the workplace are encouragements in the form of motivation from managers, time management, involvement of stakeholders in the designing of the intervention and reminders ${ }^{38}$ Use of ICT has been documented to be effective in promoting health behaviours. ${ }^{50} 53$ Comprehensive health-promoting lifestyle behaviours and ICT reduce BMI and improve physical and mental component summary. ${ }^{18}$ There is a need to examine the long-term effectiveness of ICT on health-promoting behaviours. ${ }^{54}$ To ascertain the effectiveness of ICT and comprehensive health-promoting behaviours in the prevention of diseases, there is a need to consider other health assessment parameters such as blood pressure and biochemical parameter instead of BMI alone. ${ }^{18}$

\section{DISCUSSION}

We conducted a systematic scoping review of the available studies on the use of ICT for stress management, interpersonal relations, nutrition, self-actualisation/spiritual growth, health responsibility and PA lifestyle behaviours globally. Health-promoting lifestyle behaviours play an essential role in the prevention of diseases and quality of life. ${ }^{12}{ }^{15}$ According to the WHO, to control NCDs it is important to reduce risk factors associated with them by adopting health-promoting lifestyle behaviours. ${ }^{2}$ Our systematic scoping review showed that various forms of ICT such as email, SNSs, websites, SMS or text messages, mobile phone app, smartphones, computers and MMS were used for a range of health-promoting lifestyle behaviours such as nutrition, PA, stress management, smoking cessation and reducing alcohol consumption. There was a paucity of data on interpersonal relationship, self-actualisation/ spiritual belief, stress management and health responsibility. However, health-related lifestyle behaviours such as condom use, breast cancer prevention and sexually transmitted diseases prevention that could have incorporated into health responsibility lifestyle behaviour were not a primary research article.

Furthermore, our study reported that use of ICT for health promotion improves and enhances health-promoting behaviours. More particularly, use of ICT for comprehensive health-promoting lifestyle behaviours was reported to result in a healthy BMI and to improve physical and mental health. However, BMI was the only physical health assessment parameter reported by the included studies. Factors such as time management, motivation and reminders are essential when designing health-promoting lifestyle behaviour for workers. There was only one primary study on the use of ICT and comprehensive health-promoting lifestyle behaviour among women. Also, the quality assessment of the primary studies included was of moderate risk. It is of interest to know that no reports on LMICs were found in the included studies. Regarding population size, our systematic review reported wide population spreads from 26 to 16948 across the study locations reported. This review showed that there is a dearth of knowledge on the use of ICT for comprehensive health-promoting lifestyle and health status.

ICT enhances the success of national health promotion and disease prevention programmes. ${ }^{57}$ Our study reported large population sizes, which demonstrates that public health promotion campaigns can be achieved through use of $\mathrm{ICT}^{58}$ since large populations can be involved in health promotion intervention programmes, which will potentially enhance achievement of the sustainable development goal of reducing premature deaths associated with NCDs to one-third by $2030 .^{2}$ However, to reduce attrition rate in ICT use for health-promoting lifestyle behaviour intervention, one of our included studies reported that reminders are critical. ${ }^{38}$ Much attention has been given to PA, nutritional lifestyle behaviours and healthy weight, and this might be the possible reason why these two lifestyle behaviours were more pronounced in our findings. This might also be the reason why only BMI was assessed among all the physical health parameters that could be of importance to control and prevention of NCDs. ${ }^{2}$ These findings have implications for the control and prevention of NCDs in the near future.

One of the strengths of this study is the extensive literature searched and the rigorous process in selecting the included studies. Scoping review as conducted for this study is an approach that examines the extent, range and nature of research activity in a particular field to identify research gap. ${ }^{33} 59$ This is the first article that has examined ICT and comprehensive health-promoting lifestyle behaviours among healthy adults, as the authors are not aware of any such others. We also conducted a methodological quality appraisal of the included primary research. Results in our study did not omit any country, as 'country filter' was not applied during the literature search. All the included articles reported on PA except one that reported only on stress management. Also, some articles reported on stress management, spiritual growth health responsibility and interpersonal relationships. Most of the included studies that reported on health responsibility-related lifestyle behaviours such as smoking cessation, reduced alcohol consumption, condom use, breast cancer prevention and sexually transmitted diseases prevention were systematically reviewed studies. However, none of the included studies reported on blood pressure or blood glucose level. Screening and early detection of NCDs are one way to prevent and control this demon called NCDs. ${ }^{2}$ In the next 30 years, there will be a 3.5 -fold increase globally in deaths due to 
cardiovascular diseases ${ }^{60}$ which are the leading cause of mortality and morbidity among all the NCDs. ${ }^{1-3}$ Highest premature deaths associated with NCDs are recorded in the LMICs. ${ }^{1261}$ However, our scoping review showed scarcity in the use of ICT for comprehensive health-promoting lifestyle behaviours research among healthy adults from these regions.

Some limitations of this study were as follows: first, inclusion of studies published in the English language between January 2007 and December 2018; second, the reference lists of the included articles were not examined, and no manual searches were performed; lastly, only electronic databases were extensively searched for the included studies.

Health-promoting lifestyle behaviour remains a crucial means of curbing the menace associated with NCDs. ${ }^{314-16}$ However, some people prefer to be busy with other issues of life rather than engaging in health-promoting lifestyle behaviour. ${ }^{14}{ }^{38}$ Hence, only a few individuals adhere to healthy lifestyle behaviour despite the role it plays in chronic diseases prevention. ${ }^{146}$ There is need to explore other means of encouraging people to practise health-promoting lifestyle behaviours because it is a fact that prevention is better than cure. Literature showed that web-based interventions are effective in changing behaviour. ${ }^{20}$ With the increase in the burden of NCDs in LMICs, ${ }^{61}$ use of ICT to promote health behaviour lifestyle is the key determinant in the control and prevention of NCDs. ${ }^{58}$ There is an urgent need to assess the nature and form of ICT that can be effective in promoting health behaviours among healthy adults in LMICs, and in Africa in particular. In addition, there is need to explore use of ICT and comprehensive health-promoting lifestyle behaviours among healthy adults in LMICs where there is a gap in the primary study of these issues.

\section{CONCLUSION}

The findings from our study showed that ICT in relation to health-promoting lifestyle behaviour enhances health-promoting lifestyle behaviour and promotes physical and mental health. PA was assessed by all the included studies except for one that examined stress management. BMI was the only physical health parameter reported by one of the included studies. Factors such as time management, motivation and reminders are important when designing health-promoting lifestyle behaviour for the worker. None of the included studies reported on LMICs. There is a dearth of knowledge on a comprehensive health-promoting behaviour that can be beneficial in the control and prevention of NCDs. There is need to carry out primary studies on the use of ICT for a comprehensive health-promoting lifestyle, especially among 'healthy' adults in LMICs where there are alarming statistics on the mortality and disability associated with NCDs.

Acknowledgements The authors acknowledge the contribution of Mr Joseph Shehu for offering technical assistance related to information and communication technologies.
Collaborators Ncama BP, Mooi N, Mashamba-Thompson TP.

Contributors Dr EMJ-S conceptualised, designed the protocol and prepared the draft of the manuscript under the supervision of Professor BPN. Ms NM and Dr TPMT contributed to the methodology and data collection. All authors critically reviewed the draft version of the manuscript and gave approval for submission.

Funding The authors have not declared a specific grant for this research from any funding agency in the public, commercial or not-for-profit sectors.

Competing interests None declared.

Patient consent for publication Not required.

Provenance and peer review Not commissioned; externally peer reviewed.

Data availability statement All data relevant to the study are included in the article or uploaded as supplementary information.

Open access This is an open access article distributed in accordance with the Creative Commons Attribution Non Commercial (CC BY-NC 4.0) license, which permits others to distribute, remix, adapt, build upon this work non-commercially, and license their derivative works on different terms, provided the original work is properly cited, appropriate credit is given, any changes made indicated, and the use is non-commercial. See: http://creativecommons.org/licenses/by-nc/4.0/.

\section{ORCID iDs}

Elizabeth Musili Joseph-Shehu http://orcid.org/0000-0002-9356-4555

Nomaxabiso Mooi http://orcid.org/0000-0002-2565-5981

Tivani Phosa Mashamba-Thompson http://orcid.org/0000-0002-4193-2416

\section{REFERENCES}

1 Ali MK, Jaacks LM, Kowalski AJ, et al. Noncommunicable diseases: three decades of global data show a mixture of increases and decreases in mortality rates. Health Aff 2015;34:1444-55.

2 WHO. Noncommunicable diseases, 2017. Available: http://www.who. int/mediacentre/factsheets/fs355/en/ [Accessed 27/05/2017].

3 Joseph-Shehu EM, Ncama BP. Evidence on health-promoting lifestyle practices and information and communication technologies: Scoping review protocol. BMJ Open 2017;7:e014358.

4 Murray CJ, Lopez AD, World Health Organization. The global burden of disease: a comprehensive assessment of mortality and disability from diseases, injuries, and risk factors in 1990 and projected to 2020. Summary 1996.

5 Mokdad A. Global non-communicable disease prevention: building on success by addressing an emerging health need in developing countries. Journal of Health Specialties 2016;4

6 Ding D, Lawson KD, Kolbe-Alexander TL, et al. The economic burden of physical inactivity: a global analysis of major non-communicable diseases. The Lancet 2016;388:1311-24.

7 Ulla Diez SM, Perez-Fortis A. Socio-Demographic predictors of health behaviors in Mexican college students. Health Promot Int 2010;25:85-93

8 El Ansari W, Stock C, John J, et al. Health promoting behaviours and lifestyle characteristics of students at seven universities in the UK. Cent Eur J Public Health 2011;19:197-204

9 Beaglehole R, Bonita R, Horton R, et al. Priority actions for the noncommunicable disease crisis. The Lancet 2011;377:1438-47.

10 Burniston J, Eftekhari F, Hrabi S, et al. Health behaviour change and lifestyle-related condition prevalence: comparison of two epochs based on systematic review of the physical therapy literature. Hong Kong Physiotherapy Journal 2012;30:44-56.

11 Sorour AS, Kamel WW, Abd El- Aziz EM, et al. Health promoting lifestyle behaviors and related risk factors among female employees in Zagazig City. Journal of Nursing Education and Practice 2014;4:42-51.

12 Tol A, Tavassoli E, Shariferad GR, et al. Health-Promoting lifestyle and quality of life among undergraduate students at school of health, Isfahan University of medical sciences. J Educ Health Promot 2013;2:11.

13 Turkmen M, Ozkan A, Murat K, et al. Investigation of the relationship between physical activity level and healthy life-style behaviors of academic staff. Educational Research and Reviews 2015;10:577-81.

14 Shehu RA, Onasanya SA, Onigbinde TA, et al. Lifestyle, fitness and health promotion initiative of the University of Ilorin, Nigeria: an educational media intervention. Ethiopian Journal of Environmental Studies and Management 2013;6:273-9.

15 Bully P, Sánchez Álvaro, Zabaleta-del-OImo E, et al. Evidence from interventions based on theoretical models for lifestyle modification 
(physical activity, diet, alcohol and tobacco use) in primary care settings: a systematic review. Prev Med 2015;76:S76-93.

16 Artinian NT, Fletcher GF, Mozaffarian D, et al. Interventions to promote physical activity and dietary lifestyle changes for cardiovascular risk factor reduction in adults a scientific statement from the American heart association. Circulation 2010:406-41.

17 Laranjo L, Arguel A, Neves AL, et al. The influence of socia networking sites on health behavior change: a systematic review and meta-analysis. Journal of the American Medical Informatics Association 2014.

18 Tsai Y-C, Liu C-H. An eHealth education intervention to promote healthy lifestyles among nurses. Nurs Outlook 2015;63:245-54.

19 Greene GW, Fey-Yensan N, Padula C, et al. Change in fruit and vegetable intake over 24 months in older adults: results of the senior project intervention. Gerontologist 2008;48:378-87.

20 Naimark JS, Madar Z, Shahar DR. The impact of a web-based APP (eBalance) in promoting healthy lifestyles: randomized controlled trial. Journal of medical Internet research 2015;17.

21 Christensson P. Ict definition, 2010. Available: https://techterms.com [Accessed 9 September 2017].

22 Barak A, Hen L, Boniel-Nissim M, et al. A comprehensive review and a meta-analysis of the effectiveness of Internetbased psychotherapeutic interventions. J Technol Hum Serv 2008;26:109-60.

23 Wilkinson N, Ang RP, Goh DH. Online video game therapy for mental health concerns: a review. International Journal of Social Psychiatry 2008;54:370-82.

24 Bosworth HB, Olsen MK, McCant F, et al. Hypertension intervention nurse telemedicine study (hints): testing a multifactorial tailored behavioral/educational and a medication management intervention for blood pressure control. Am Heart J 2007;153:918-24.

25 Klasnja P, Pratt W. Healthcare in the pocket: mapping the space of mobile-phone health interventions. J Biomed Inform 2012;45:184-98.

26 Muessig KE, Pike EC, LeGrand S, et al. Mobile phone applications for the care and prevention of HIV and other sexually transmitted diseases: a review. J Med Internet Res 2013;15:e1.

27 Fanning J, Mullen SP, McAuley E. Increasing physical activity with mobile devices: a meta-analysis. J Med Internet Res 2012;14:e161

28 Free C, Phillips G, Galli L, et al. The effectiveness of mobile-health technology-based health behaviour change or disease management interventions for health care consumers: a systematic review. PLOS Med 2013;10:e1001362.

29 Bauermeister JA, Zimmerman MA, Johns MM, et al. Innovative recruitment using online networks: lessons learned from an online study of alcohol and other drug use utilizing a web-based, respondent-driven sampling (webRDS) strategy. J Stud Alcohol Drugs 2012;73:834-8.

30 Walker SN, Sechrist KR, Pender NJ. Health Promotion Model Instruments to Measure Health Promoting Lifestyle : HealthPromoting Lifestyle Profile [HPLP II] (Adult Version), 1995. Available: https:// deepblue.lib.umich.edu/handle/2027.42/85349 [Accessed 08 July 2015].

31 Joseph-Shehu E, Ncama B. Health-Promoting lifestyle behaviour of workers: a systematic review. Occupational Health Southern Africa 2019;25:60-6.

32 Nassar OS, Shaheen AM. Health-Promoting behaviours of university nursing students in Jordan. Health 2014;06:2756-63.

33 Arksey H, O'Malley L. Scoping studies: towards a methodological framework. Int J Soc Res Methodol 2005;8:19-32.

34 Tricco AC, Lillie E, Zarin W, et al. PRISMA extension for scoping reviews (PRISMA-ScR): checklist and explanation. Ann Intern Med 2018;169:467-73.

35 Pluye P, Robert E, Cargo M, et al. Proposal: a mixed methods appraisal tool for systematic mixed studies reviews: archived by WebCite $\AA$, 2011. Available: http://www.webcitation.org/5tTRTc9y

36 Mackenzie K, Goyder E, Eves F. Acceptability and feasibility of a low-cost, theory-based and co-produced intervention to reduce workplace sitting time in desk-based university employees. BMC Public Health 2015;15:1294-94.

37 Lara J, O'Brien N, Godfrey A, et al. Pilot randomised controlled trial of a web-based intervention to promote healthy eating, physical activity and meaningful social connections compared with usual care control in people of retirement age recruited from workplaces. PLOS One 2016;11:e0159703-17.
38 Bardus M, Blake H, Lloyd S, et al. Reasons for participating and not participating in a e-health workplace physical activity intervention. International Journal of Workplace Health Management 2014;7:229-46.

39 Ammann R, Vandelanotte $\mathrm{C}$, De Vries $\mathrm{H}$, et al. Can a websitedelivered computer-tailored physical activity intervention be acceptable, usable, and effective for older people? Health Education \& Behavior 2012;1090198112461791.

40 Frank LL, McCarthy MS. Telehealth coaching: impact on dietary and physical activity contributions to bone health during a military deployment. Mil Med 2016;181:191-8.

41 Guertler D, Vandelanotte C, Kirwan M, et al. Engagement and nonusage attrition with a free physical activity promotion program: the case of 10,000 steps Australia. J Med Internet Res 2015;17:e176.

42 Schneider F, Schulz DN, Pouwels LHL, et al. The use of a proactive dissemination strategy to optimize reach of an internet-delivered computer tailored lifestyle intervention. BMC Public Health 2013;13:1.

43 Carr LJ, Leonhard C, Tucker S, et al. Total worker health intervention increases activity of sedentary workers. American journal of preventive medicine 2015.

44 King AC, Hekler EB, Grieco LA, et al. Effects of three Motivationally targeted mobile device applications on initial physical activity and sedentary behavior change in midlife and older adults: a randomized trial. PLoS One 2016;11:e0156370-16.

45 Kirwan M, Duncan MJ, Vandelanotte C, et al. Using smartphone technology to monitor physical activity in the 10,000 steps program: a matched case-control trial. J Med Internet Res 2012;14:e55.

46 Schneider F, de Vries H, Candel M, et al. Periodic email prompts to re-use an internet-delivered computer-tailored lifestyle program: influence of prompt content and timing. J Med Internet Res 2013;15:e23.

47 Howarth A, Quesada J, Silva J, et al. The impact of digital health interventions on health-related outcomes in the workplace: a systematic review. Digital Health 2018;4.

48 Carr LJ, Dunsiger SI, Lewis B, et al. Randomized controlled trial testing an Internet physical activity intervention for sedentary adults. Health Psychology 2013;32:328-36.

49 Bardus M, Smith JR, Samaha L, et al. Mobile phone and web 2.0 technologies for weight management: a systematic scoping review. $J$ Med Internet Res 2015;17:e259.

50 Stratton E, Lampit A, Choi I, et al. Effectiveness of eHealth interventions for reducing mental health conditions in employees: a systematic review and meta-analysis. PLoS One 2017;12:e0189904.

51 Bert F, Giacometti M, Gualano MR, et al. Smartphones and health promotion: a review of the evidence. J Med Syst 2014;38:1-11.

52 Buhi ER, Trudnak TE, Martinasek MP, et al. Mobile phone-based behavioural interventions for health: a systematic review. Health Educ $J$ 2013;72:564-83.

53 Hou S-I, Charlery S-AR, Roberson K. Systematic literature review of internet interventions across health behaviors. Health Psychology and Behavioral Medicine 2014;2:455-81.

54 Kohl LFM, Crutzen R, de Vries NK. Online prevention aimed at lifestyle behaviors: a systematic review of reviews. J Med Internet Res 2013;15:e146.

55 Rogers MAM, Lemmen K, Kramer R, et al. Internet-Delivered health interventions that work: systematic review of meta-analyses and evaluation of website availability. J Med Internet Res 2017;19:e90.

56 Lee M, Lee H, Kim Y, et al. Mobile app-based health promotion programs: a systematic review of the literature. Int $J$ Environ Res Public Health 2018;15:2838.

57 Haluza D, Jungwirth D. Ict and the future of health care: aspects of health promotion. Int $J$ Med Inform 2015;84:48-57.

58 Honka A, Kaipainen $\mathrm{K}$, Hietala $\mathrm{H}$, et al. Rethinking health: ICTenabled services to empower people to manage their health. IEEE Rev Biomed Eng 2011;4:119-39.

59 Assaram S, Magula NP, Mewa Kinoo S, et al. Renal manifestations of HIV during the antiretroviral era in South Africa: a systematic scoping review. Syst Rev 2017;6:200.

60 Cipriano G, Neves LMT, Cipriano GFB, et al. Cardiovascular disease prevention and implications for worksite health promotion programs in Brazil. Prog Cardiovasc Dis 2014;56:493-500.

61 Alwan A, MacLean DR, Riley LM, et al. Monitoring and surveillance of chronic non-communicable diseases: progress and capacity in highburden countries. The Lancet 2010;376:1861-8. 